\title{
FRAÇÕES ORGÂNICAS E MINERAL NA PRODUÇÃO DE MUDAS DE MAMOEIRO ${ }^{1}$
}

\author{
MARCUS VINICIUS SANDOVAL PAIXÃO², EDILSON ROMAIS SCHMILDT ${ }^{3}$, \\ HEDIBERTO NEI MATTIELLO ${ }^{2}$, GERALDO ANTÔNIO FERREGUETTI ${ }^{4}$, \\ RODRIGO SOBREIRA ALEXANDRE ${ }^{3}$
}

RESUMO - O objetivo deste trabalho foi avaliar o efeito de diferentes doses de esterco de galinha associadas ao adubo superfosfato simples, em substituição à formulação empregada no norte do Espírito Santo, na produção de mudas de mamoeiro 'THB'. O experimento foi realizado no viveiro agrícola, na Empresa Caliman Agrícola S.A., no município de Linhares-ES. Adotou-se o delineamento estatístico em blocos casualizados, em esquema fatorial $5 \times 5$, com 5 doses de superfosfato simples $\left(0 ; 5 ; 10 ; 15\right.$ e $\left.20 \mathrm{~kg} \mathrm{~m}^{-3}\right)$ e 5 doses de esterco de galinha $(0 ; 10 ; 20 ; 30$ e $40 \%$ v/vt), além de uma testemunha adicional, constituída da mistura-padrão utilizada na região com o adubo Basacote mini $3 \mathrm{M}^{\circledR}$, fórmula NPK $(\mathrm{mg}) 13-06-16(1,4)$, com micronutrientes $(10 \%$ $\mathrm{S}, 0,05 \% \mathrm{Cu}, 0,26 \% \mathrm{Mn}$ e $0,015 \% \mathrm{Mo}$ ) na dosagem de $10 \mathrm{~kg} \mathrm{~m}^{-3}$, com 4 repetições. O substrato utilizado foi o Bioplant ${ }^{\mathbb{R}}$. Para comparação, avaliaram-se a \% de emergência, o índice de velocidade de emergência, o tempo médio de emergência, o índice de teor de clorofila, altura, diâmetro do coleto, número de folhas, comprimento da raiz, massa seca de raízes e de parte aérea das plântulas. Conclui-se que o tratamento-padrão com substrato Bioplant ${ }^{\circledR}$, associado ao fertilizante Basocote ${ }^{\circledR}$, apresentou-se como o melhor para a produção de mudas do mamoeiro 'THB', desaconselhando-se o uso do esterco de galinha na mistura com substrato. A aplicação do fertilizante superfosfato simples não melhorou a qualidade das mudas em relação ao padrão.

Termos para indexação: Carica papaya L., esterco de galinha, superfosfato simples.

\section{ORGANIC AND MINERAL FRACTIONS IN THE PRODUCTION OF PAPAYA SEEDLINGS}

\begin{abstract}
The objective of this study was to evaluate the effect of different dosage of chicken manure associated with the superphosphate fertilizer, replacing the formulation used in the north of Espírito Santo, the production of 'THB' papaya seedlings. The experiment was conducted in an agricultural nursery, of the Company Caliman Agricola SA, in Linhares-ES in randomized block design in a factorial $5 \times 5$ (superphosphate: $0,5,10,15,20 \mathrm{~kg} \mathrm{~m}^{-3} \mathrm{x}$ chicken manure: $0,10,20,30,40 \% \mathrm{v} / \mathrm{vt}$ ) with additional witness consisting of the standard mixture used in the region with $3 \mathrm{M}^{\circledR}$ mini Basacote fertilizer, NPK (mg) 13-0616 (1.4) with micronutrients $(10 \% \mathrm{~S}, 0.05 \% \mathrm{Cu}, 0.26 \% \mathrm{Mn}, 0.015 \% \mathrm{Mo})$ at a dosage of $10 \mathrm{~kg} \mathrm{~m}^{-3}$, with 4 repetitions. The substrate was Bioplant ${ }^{\circledR}$. It was evaluated the $\%$ of emergency, the emergency speed index and the emergency average time, the rate of chlorophyll content, seedling height, stem diameter, leaf number, root length, dry mass of roots and shoot. It is concluded that the standard treatment of substrate and fertilizer Basocote Bioplant ${ }^{\mathbb{R}}$, presented itself as the best for production of 'THB' papaya seedlings and discouraged the use of chicken manure mixed with the substrate. The application of superphosphate fertilizer did not improve the quality of the seedlings from the default.
\end{abstract}

Index terms: Carica papaya L., chicken manure, superphosphate.

${ }^{1}$ (Trabalho 108-12). Recebido em: 19-03-2012. Aceito para publicação em: 25-09-2012.

${ }^{2}$ Prof. do IFES, Campus Santa Teresa, São João de Petrópolis, Santa Teresa-ES, CEP 29660.000. E-mail: mvspaixao@bol.com.br, hedibertonm@ifes.edu.br

${ }^{3}$ Prof. Departamento de Ciências Agrárias e Biológicas (DCAB), do Centro Universitário Norte do Espírito Santo (CEUNES)/Universidade Federal do Espírito Santo (UFES). Rodovia BR 101 Norte, Km. 60, Bairro Litorâneo, CEP 29932-540, São Mateus-ES. E-mail: edilsonschmildt@ceunes.ufes.br, rodrigosobreiraalexandre@gmail.com

${ }^{4}$ Eng. ${ }^{\circ}$ Agrônomo, Diretor Agrícola da Caliman Agrícola S/A, BR 101, Km 111, Caixa Postal 52, 29900-970, Linhares-ES. E-mail: geraldo@caliman.com.br 


\section{INTRODUÇÃO}

O mamoeiro (Carica papaya L.) é uma planta cujo fruto tem grande importância econômica, alimentícia e social, sendo cultivado principalmente nos países tropicais. A participação brasileira na produção mundial de mamão, em 2010, foi da ordem de $16,67 \%$, com um volume de 1,87 milhão de toneladas de frutos (FAO, 2012), produzidos principalmente nos Estados da Bahia, Espírito Santo, Ceará e Rio Grande do Norte. O sistema de produção inicia-se com mudas de qualidade obtidas através da escolha de adequado sistema de irrigação, recipientes, substratos e fertilizantes principalmente os de liberação lenta, dentre outros.

No Espírito Santo, a variação de substratos na produção de mudas é grande, variando do uso de mistura de solo com esterco, adicionando fertilizantes (NPK), ao uso de substrato comercial, adicionando fertilizantes de liberação lenta, sendo também utilizado esterco de curral. Entretanto, na produção de mudas em substratos comerciais, há necessidade de aplicações frequentes de nutrientes, devido principalmente à sua lixiviação. Assim, a utilização de adubos que apresentam liberação controlada dos nutrientes torna-se uma das alternativas para aumentar a eficiência das adubações (SERRANO et al., 2010). A utilização de adubos de liberação lenta também permite ao produtor de mudas uma redução de gastos com mão de obra com a aplicação de fertilizantes, uma vez que, para determinadas espécies, é necessária apenas a mistura destes ao substrato (PEREIRA et al., 2000; LANA et al., 2002; SERRANO et al., 2006). Serrano et al. (2010), em trabalhos com mudas de mamoeiro, utilizando o adubo de liberação lenta, fórmula NPK (mg) 13-06-16 $(1,4)$, adicionado ao substrato comercial, concluíram que, dependendo da variedade, nas doses entre 7,9 e 11,3 $\mathrm{kg} \mathrm{m}^{-3}$, as mudas de mamoeiro apresentaram-se com adequado estado nutricional.

A matéria orgânica é componente fundamental da capacidade produtiva dos solos, por causa de seus efeitos sobre a disponibilidade de nutrientes, CTC, complexação de elementos tóxicos e micronutrientes, agregação, infiltração e retenção de água, aeração e atividade de biomassa microbiana (BAYER; MIELNICZUK, 2008).

Mendonça et al. (2006a,b) verificaram que o superfosfato simples responde de maneira positiva quando utilizado na formulação do substrato para formação de mudas de mamoeiro 'Formosa' até dosagens de $10 \mathrm{~kg} \mathrm{~m}^{-3}$.

O objetivo deste trabalho foi avaliar o efeito de diferentes doses de esterco de galinha associados ao adubo superfosfato simples, em substituição à formulação empregada na região, na produção de mudas de mamoeiro 'THB'.

\section{MATERIAL E MÉTODOS}

O experimento foi realizado com o mamoeiro 'THB', uma linhagem pura do grupo 'Solo'. As mudas foram preparadas em estufa agrícola, na Empresa Caliman Agrícola S.A., em Linhares-ES. Adotou-se o delineamento estatístico de blocos casualizados, em esquema fatorial $5 \times 5$, com 5 doses de superfosfato simples $\left(0 ; 5 ; 10 ; 15\right.$ e $\left.20 \mathrm{~kg} \mathrm{~m}^{-3}\right)$ e 5 doses de esterco de galinha $(0 ; 10 ; 20 ; 30$ e $40 \%$ v/ vt), além de uma testemunha adicional, constituída da mistura- padrão utilizada na região com o adubo Basacote mini $3 \mathrm{M}^{\circledR}$, fórmula NPK (mg) 13-06-16 $(1,4)$, com micronutrientes $(10 \% \mathrm{~S}, 0,05 \% \mathrm{Cu}$, $0,26 \%$ Mn e $0,015 \% \mathrm{Mo}$ ), na dosagem de $10 \mathrm{~kg}$ $\mathrm{m}^{-3}$, com 4 repetições. A caracterização química dos substratos encontra-se na Tabela 1. Os tratamentos foram dispostos em canteiros (blocos), formados por 60 bandejas,com capacidade para 96 tubetes de $50 \mathrm{~cm}^{3}$, preenchidos com o substrato Bioplant ${ }^{\mathbb{R}}$. Ao longo do canteiro, havia uma parcela experimental de cada tratamento, composta por 48 plântulas, das quais as 10 centrais foram avaliadas.

No ato da semeadura, colocou-se uma semente por tubete. Durante toda a condução, diariamente, irrigou-se a unidade experimental por meio do sistema de microaspersão. Neste período, avaliaram-se a porcentagem de emergência, o índice de velocidade de emergência (IVE) (MAGUIRE, 1962) e o tempo médio de emergência (TME) (LABORIAU; VALADARES, 1976).

Passados 30 dias após semeadura, mediramse o índice de teor de clorofila, altura $(\mathrm{cm})$, diâmetro do coleto $(\mathrm{mm})$, número de folhas, comprimento da raiz $(\mathrm{cm})$ e massa seca da parte aérea e de raízes (mg) das plântulas.

Os dados foram submetidos à análise de variância; e as médias, comparadas pelo teste de Tukey,a 5\% de probabilidade, e análise de regressão com ajuste polinomial. As análises foram feitas com auxílio do programa GENES (CRUZ, 2006).

\section{RESULTADOS E DISCUSSÃO}

Nos tratamentos com variações de esterco/ superfosfato simples e a testemunha (padrão), não foram observadas diferenças para a variável porcentagem de emergência das plântulas que apresentou valor médio de $75,79 \%$. Entretanto, foram observadas diferenças significativas para o IVE e TME 
entre esterco e o padrão (Tabela 2). Variações quanto à germinação de sementes e crescimento de mudas de mamoeiros dependem de uma série de fatores, como estádio de maturação de frutos, época de colheita (TOKUHISA et al., 2008), repouso dos frutos (MARTINS et al., 2006), secagem, armazenamento (DIAS et al., 2010), constituição química das sementes (TOKUHISA et al., 2007), fenômeno de xênia (MARTINS et al., 2009) e adubação (SERRANO et al., 2010).

Observa-se, na Tabela 02, de acordo com os valores do índice de velocidade de emergência das plântulas, que nos tratamentos contendo esterco de galinha este parâmetro foi superior ao tratamento-padrão. Consequentemente, o tempo médio de emergência destas plântulas foi menor ao empregar o esterco de galinha; todavia, não atingindo um dia de antecipação. Quanto ao índice de clorofila e ao número de folhas/plântula, com apenas o substrato-padrão, nota-se que estes foram superiores se este foi adicionado de esterco, possibilitando, além do dobro do índice de clorofila, uma folha a mais por plântula. Tal resposta permite inferir que a formulação-padrão com Basacote mini $3 \mathrm{M}^{\circledR}$, fórmula NPK (mg) 13-0616 , possivelmente pelo maior teor de nitrogênio, é suficiente na produção de mudas do mamoeiro 'THB', conforme citado por Serrano et al. (2010), também, na produção de mudas das variedades ou cultivares 'Golden', 'Calimosa', 'Tainung 01', 'Incaper 09' e 'Incaper 39'.

Na tabela 3, observa-se que o número de folhas por plântula é reduzido com a adição de esterco de galinha no substrato. A maior redução média, de 3,5 para 2,0 folhas por plântula, deu- se com esterco entre 28,0 e $39,5 \%$ no substrato. Por outro lado, ao se usar $10 \%$ de esterco no substrato, o número de folhas por plântula apresentou comportamento quadrático em resposta à aplicação de superfosfato simples, com ponto de máximo em $16 \mathrm{~kg} \mathrm{~m}^{-3}$ do adubo, o que correspondeu acerca de 2,88 folhas por plântula. No entanto, este número é ainda inferior ao padrão e ao substrato sem esterco, que apresentaram, respectivamente, 3,83 e 3,48 folhas por plântula em média. Portanto, não se aconselha o uso do esterco nem do superfosfato simples no substrato.

$\mathrm{O}$ índice do teor de clorofila foi cerca de três vezes mais elevado na formulação- padrão, utilizando Basacote ${ }^{\circledR}$ e NPK em relação aos demais tratamentos (Tabela 4). Apesar de os teores nutricionais encontrados no esterco de galinha estarem na faixa de médio a alto, o $\mathrm{pH}$ foi de 9,31, o que poderia ter dificultado a absorção de micronutrientes pelas plântulas do mamoeiro 'THB'. Segundo Abad et al. (2001), a faixa de $\mathrm{pH}$ de 5,3-6,5 é considerada ideal para os componentes de substratos usados na produção de mudas em recipientes. Higashikawa et al. (2010) encontraram, em esterco de galinha, $\mathrm{pH}$ acima de 7 , valor este superior à faixa ideal, como no presente trabalho.

As plântulas apresentaram maior crescimento de parte aérea tanto em altura quanto em diâmetro, no substrato-padrão. A altura da plântula não diferiu estatisticamente quando se utilizaram os substratos-padrão e a ausência de esterco de galinha (Tabela 5). O mesmo foi observado com relação à massa de matéria seca do sistema radicular, onde o substrato- padrão e a ausência de esterco de galinha apresentaram os melhores resultados, não diferindo estatisticamente entre si. Já para o crescimento de raiz, o melhor tratamento foi à ausência de esterco de galinha, que não diferiu estatisticamente ao usar $10 \%$ e $20 \%$ de esterco de galinha e do substrato-padrão. Observa-se neste trabalho que, possivelmente, o $\mathrm{pH}$ alto do esterco, com alta $\%$ de cálcio, fez com que as plântulas desenvolvessem raízes em comprimento, porém pode ser observado que a massa seca das raízes é reduzida em relação ao padrão, à medida que se aumenta a dosagem de esterco na mistura. Em relação ao comprimento das raízes, Rosolem et al. (1999) citam que a capacidade de absorção de nutrientes está relacionada com o comprimento radicular, e Negreiros et al. (2005), trabalhando com substratos, em sacos de polietileno, citam que o maior comprimento e desenvolvimento da raiz no Plantmax ${ }^{\circledR}$ podem estar relacionados ao maior teor do elemento cálcio, o qual é importante para o crescimento radicular.

Outros substratos também se destacam, como a vermiculita adubada com $14 \%$ de Organosuper ${ }^{\circledR}$, na formação de mudas do mamoeiro 'Sunrise Solo' (COSTA et al., 2010a,b). Costa et al. (2011) mostraram que a adição de Organosuper ${ }^{\circledR}$ a 7; 14 e 21\%, resultou em plântulas de mamoeiro 'Sunrise Solo' de qualidade superior. Isto mostra que, apesar de o esterco de galinha não ter sido representativo na produção de mudas do mamoeiro 'THB' (Tabela 4), outros compostos orgânicos podem apresentar efeito positivo. Segundo Araújo et al. (2010), a mistura de terra $(30 \%)+$ Plantmax $^{\circledR}(35 \%)+$ esterco caprino $(35 \%)$ foi a ideal para o crescimento da parte aérea e do sistema radicular de plântulas de mamoeiro 'Sunrise Solo'.

A inserção de superfosfato simples ao substrato, seja na mistura com o padrão, seja com o esterco de galinha, não resultou em melhoras na massa seca da parte aérea, indicando a não recomendação do mesmo nestas concentrações (Figura 1). Segundo Canesin e Côrrea (2006), por outro lado, o esterco 
de curral pode ser utilizado sem a necessidade de adubação mineral com o superfosfato simples na formação de mudas do mamoeiro 'Sunrise Solo
Line 72/12', diferentemente do observado no presente trabalho.

TABELA 1 - Constituição química do substrato Bioplant ${ }^{\mathbb{R}}$ e do esterco de galinha adotados no estudo.

\begin{tabular}{lcc}
\hline Constituinte & Esterco & Bioplant $^{\circledR}$ \\
\hline Nitrogênio $(\mathrm{N})$ & $1,95(\%)$ & $0,62(\%)$ \\
Fósforo $\left(\mathrm{P}_{2} \mathrm{O}_{5}\right)$ & $6,92(\%)$ & $3,55(\%)$ \\
Potássio $\left(\mathrm{K}_{2} \mathrm{O}\right)$ & $3,24(\%)$ & $0,53(\%)$ \\
Cálcio $(\mathrm{Ca})$ & $11,10(\%)$ & $1,84(\%)$ \\
Magnésio $(\mathrm{Mg})$ & $0,94(\%)$ & $0,43(\%)$ \\
Enxofre (S) & $0,43(\%)$ & $0,55(\%)$ \\
Ferro $(\mathrm{Fe})$ & $0,45(\%)$ & $2,36(\%)$ \\
Zinco $(\mathrm{Zn})$ & $540,0 \mathrm{ppm}$ & $99,8 \mathrm{ppm}$ \\
Cobre $(\mathrm{Cu})$ & $450,0 \mathrm{ppm}$ & $75,0 \mathrm{ppm}$ \\
Manganês $(\mathrm{Mn})$ & $484,1 \mathrm{ppm}$ & $333,5 \mathrm{ppm}$ \\
Boro (B) & $27,1 \mathrm{ppm}$ & $34,5 \mathrm{ppm}$ \\
Matéria Orgânica Total & $48,06(\%)$ & $52,21(\%)$ \\
Matéria Orgânica Compostável & $40,50(\%)$ & $37,80(\%)$ \\
Carbono Orgânico & $22,50(\%)$ & $21,00(\%)$ \\
Relação C/N & $12 / 1$ & $34 / 1$ \\
pH em CaCl & 9,31 & 5,62 \\
\hline
\end{tabular}

TABELA 2 - Índice de velocidade de emergência (IVE), tempo médio de emergência (TME, dias), número de folhas (NF) e índice de clorofila (IC) de plântulas de mamoeiro 'THB', em substratos suplementados com diferentes doses de esterco de galinha e padrão.

\begin{tabular}{ccccc}
\hline \multirow{2}{*}{ Adubos } & \multicolumn{4}{c}{ Características avaliadas ${ }^{*}$} \\
\cline { 2 - 5 } & IVE & TME (dias) & NF & IC \\
\hline Esterco & $2,20 \mathrm{a}$ & $16,92 \mathrm{~b}$ & $2,44 \mathrm{~b}$ & $24,88 \mathrm{~b}$ \\
Padrão & $2,01 \mathrm{~b}$ & $17,42 \mathrm{a}$ & $3,83 \mathrm{a}$ & $53,15 \mathrm{a}$ \\
\hline DMS & 0,17 & 0,48 & 0,19 & 2,44 \\
\hline
\end{tabular}

* Médias seguidas da mesma letra, na coluna, não diferem entre si, pelo teste de Tukey, a $5 \%$ de probabilidade. 
TABELA 3 - Equações ajustadas, coeficiente de determinação $\left(\mathrm{R}^{2}\right)$ e ponto de mínimo e de máximo para número de folhas (NF) por plântula de mamoeiro "THB”, aos 30 dias, em função de doses de superfosfato simples (SS), esterco de galinha (E) e padrão no substrato.

\begin{tabular}{|c|c|c|c|c|}
\hline \multirow{2}{*}{$\begin{array}{l}\text { Nível do Fator SS } \\
\qquad\left(\mathrm{kg} \mathrm{m}^{-3}\right)\end{array}$} & \multirow{2}{*}{$\begin{array}{l}\text { Equações ajustadas } \\
\left(\hat{Y}_{\mathrm{i}}=\mathrm{X}_{\mathrm{i}}=\mathrm{E}, \mathrm{em} \%\right)\end{array}$} & \multirow{2}{*}{$\mathrm{R}^{2}(\%)$} & \multicolumn{2}{|c|}{ Ponto de mínimo } \\
\hline & & & E & $\mathrm{NF}$ \\
\hline $0 \mathrm{SS}$ & $\overline{\mathrm{Y}}_{\mathrm{i}}=3,35-0,0958^{-*} \mathrm{X}_{\mathrm{i}}+0,0016^{-1} \mathrm{X}_{\mathrm{i}}^{2}$ & 97,5 & 29,94 & 1,91 \\
\hline $5 \mathrm{SS}$ & $\hat{\mathrm{Y}}_{\mathrm{i}}=3,14-0,0912^{4 *} \mathrm{X}_{\mathrm{i}}+0,0016^{4 *} \mathrm{X}_{\mathrm{i}}^{2}$ & 82,7 & 28,50 & 1,84 \\
\hline $10 \mathrm{SS}$ & $\hat{\mathrm{Y}}_{\mathrm{i}}=3,60-0,1288^{4 *} \mathrm{X}_{\mathrm{i}}+0,0023^{4 *} \mathrm{X}_{\mathrm{i}}^{2}$ & 84,9 & 28,00 & 1,80 \\
\hline $15 \mathrm{SS}$ & $\hat{\mathrm{Y}}_{\mathrm{i}}=3,55-0,0871^{* *} \mathrm{X}_{\mathrm{i}}+0,0012^{* *} \mathrm{X}_{\mathrm{i}}^{2}$ & 94,9 & 36,29 & 1,97 \\
\hline $20 \mathrm{SS}$ & $\hat{Y}_{\mathrm{i}}=3,50-0,0790^{4 *} \mathrm{X}_{\mathrm{i}}+0,0010^{4 *} \mathrm{X}_{\mathrm{i}}^{2}$ & 98,7 & 39,50 & 1,94 \\
\hline \multirow{2}{*}{$\begin{array}{l}\text { Nível do Fator E } \\
\qquad(\%)\end{array}$} & \multirow{2}{*}{$\begin{array}{c}\quad \text { Equações ajustadas } \\
\left(\hat{\mathrm{Y}}_{\mathrm{i}}=\mathrm{NF} ; \mathrm{X}_{\mathrm{i}}=\mathrm{SS}, \mathrm{em} \mathrm{kg} \mathrm{m}^{-3}\right)\end{array}$} & \multirow{2}{*}{$\mathrm{R}^{2}(\%)$} & \multicolumn{2}{|c|}{ Ponto de máximo } \\
\hline & & & SS & NF \\
\hline $0 \mathrm{E}$ & $\hat{\mathrm{Y}}_{\mathrm{i}}=3,485$ & - & - & 3,48 \\
\hline $10 \mathrm{E}$ & $\hat{\mathrm{Y}}_{\mathrm{i}}=2,07+0,1037^{+*} \mathrm{X}_{\mathrm{i}}-0,0033^{*} \mathrm{X}_{\mathrm{i}}^{2}$ & 74,6 & 15,71 & 2,88 \\
\hline $20 \mathrm{E}$ & $\hat{\mathrm{Y}}_{\mathrm{i}}=2,13$ & - & - & 2,13 \\
\hline $30 \mathrm{E}$ & $\hat{\mathrm{Y}}_{\mathrm{i}}=2,04$ & - & - & 2,04 \\
\hline $40 \mathrm{E}$ & $\hat{\mathrm{Y}}_{\mathrm{i}}=2,01$ & - & - & 2,02 \\
\hline Padrão & $\hat{\mathrm{Y}}_{\mathrm{i}}=3,83$ & - & - & 3,83 \\
\hline
\end{tabular}

*, ** Coeficiente significativo a 5 e $1 \%$, respectivamente, pelo teste de $\mathrm{t}$.

TABELA 4 - Equações ajustadas, coeficiente de determinação $\left(\mathrm{R}^{2}\right)$ e ponto de mínimo e de máximo para índice de clorofila (IC) por plântula de mamoeiro "THB", aos 30 dias, em função de doses de superfosfato simples (SS), esterco de galinha (E) e padrão no substrato.

\begin{tabular}{|c|c|c|c|c|}
\hline \multirow{2}{*}{$\begin{array}{l}\text { Nível do Fator } \\
\mathrm{SS}\left(\mathrm{kg} \mathrm{m}^{-3}\right)\end{array}$} & \multirow{2}{*}{$\begin{array}{c}\text { Equações ajustadas } \\
\left(\hat{\mathrm{Y}}_{\mathrm{i}}=\mathrm{IC} ; \mathrm{X}_{\mathrm{i}}=\mathrm{E}, \mathrm{em} \%\right)\end{array}$} & \multirow{2}{*}{$\mathrm{R}^{2}(\%)$} & \multicolumn{2}{|c|}{ Ponto de mínimo } \\
\hline & & & $\mathrm{E}$ & $\mathrm{IC}$ \\
\hline $0 \mathrm{SS}$ & $\hat{\mathrm{Y}}_{\mathrm{i}}=31,39-0,8631^{4 *} \mathrm{X}_{\mathrm{i}}+0,0170^{4 *} \mathrm{X}_{\mathrm{i}}^{2}$ & 92,8 & 25,39 & 20,43 \\
\hline $5 \mathrm{SS}$ & $\hat{\mathrm{Y}}_{\mathrm{i}}=35,93-1,1832^{4 *} \mathrm{X}_{\mathrm{i}}+0,0200^{4 *} \mathrm{X}_{\mathrm{i}}^{2}$ & 96,8 & 29,58 & 18,43 \\
\hline $10 \mathrm{SS}$ & $\hat{\mathrm{Y}}_{\mathrm{i}}=36,14-1,0240^{* *} \mathrm{X}_{\mathrm{i}}+0,0149^{* *} \mathrm{X}_{\mathrm{i}}^{2}$ & 87,4 & 34,36 & 18,55 \\
\hline $15 \mathrm{SS}$ & $\hat{Y}_{i}=36,16-0,8990^{4 *} X_{i}+0,0121^{4 *} X_{i}^{2}$ & 97,3 & 37,15 & 19,46 \\
\hline $20 \mathrm{SS}$ & $\hat{Y}_{i}=38,86-1,2169^{* *} X_{i}+0,0187^{4 *} X_{i}^{2}$ & 98,8 & 32,54 & 19,06 \\
\hline Nível do Fator & Equações ajustadas $\left(\hat{Y}_{i}=I C ; X_{i}=S S\right.$, em kg m${ }^{-3}$ ) & $\mathrm{R}^{2}(\%)$ & \multicolumn{2}{|c|}{ Ponto de máximo } \\
\hline $\mathrm{E}(\%)$ & & $(1)(10)$ & $\mathrm{SS}$ & $\mathrm{IC}$ \\
\hline $0 \mathrm{E}$ & $\hat{\mathrm{Y}}_{\mathrm{i}}=33,24+0,3026^{* 4} \mathrm{X}_{\mathrm{i}}$ & 65,4 & 20,00 & 39,29 \\
\hline $10 \mathrm{E}$ & $\hat{Y}_{\mathrm{i}}=22,69+0,8970 \mathrm{X}_{\mathrm{i}}-0,0418^{*} \mathrm{X}_{\mathrm{i}}^{2}$ & 74,7 & 10,73 & 27,50 \\
\hline $20 \mathrm{E}$ & $\mathrm{Y}_{\mathrm{i}}=22,13$ & - & - & 22,13 \\
\hline $30 \mathrm{E}$ & $\hat{\mathrm{Y}}_{\mathrm{i}}=20,06$ & - & - & 20,06 \\
\hline $40 \mathrm{E}$ & $\hat{\mathrm{Y}}_{\mathrm{i}}=20,30$ & - & - & 20,30 \\
\hline Padrão & $\hat{\mathrm{Y}}_{\mathrm{i}}=53,15$ & - & - & 53,15 \\
\hline
\end{tabular}

$*, * *$ Coeficiente significativo a 5 e $1 \%$, respectivamente, pelo teste de $\mathrm{t}$. 
TABELA 5 - Altura da parte aérea (AP, cm), diâmetro do coleto (DC, mm), comprimento de raiz (CR, cm) e massa seca de raiz (MSR, mg) de plântulas de mamoeiro 'THB', em substratos suplementados com diferentes doses de esterco de galinha e padrão.

\begin{tabular}{lcccc}
\hline \multirow{2}{*}{ Substratos } & \multicolumn{4}{c}{ Características avaliadas } \\
\cline { 2 - 5 } & AP $(\mathrm{cm})$ & DC $(\mathrm{mm})$ & CR $(\mathrm{cm})$ & MSR $(\mathrm{mg})$ \\
\hline Esterco $(0 \% \mathrm{v} / \mathrm{vt})$ & $4,57 \mathrm{a}$ & $1,75 \mathrm{~b}$ & $14,15 \mathrm{a}$ & $22,79 \mathrm{a}$ \\
Esterco $(10 \% \mathrm{v} / \mathrm{vt})$ & $3,75 \mathrm{~b}$ & $1,29 \mathrm{c}$ & $13,36 \mathrm{ab}$ & $10,63 \mathrm{~b}$ \\
Esterco $(20 \% \mathrm{v} / \mathrm{vt})$ & $3,59 \mathrm{bc}$ & $1,15 \mathrm{~d}$ & $12,79 \mathrm{ab}$ & $8,01 \mathrm{bc}$ \\
Esterco $(30 \% \mathrm{v} / \mathrm{vt})$ & $3,40 \mathrm{c}$ & $1,10 \mathrm{~d}$ & $11,96 \mathrm{~b}$ & $6,82 \mathrm{c}$ \\
Esterco $(40 \% \mathrm{v} / \mathrm{vt})$ & $2,27 \mathrm{~d}$ & $1,03 \mathrm{~d}$ & $11,83 \mathrm{~b}$ & $6,53 \mathrm{c}$ \\
Padrão & $4,71 \mathrm{a}$ & $2,01 \mathrm{a}$ & $12,83 \mathrm{ab}$ & $25,10 \mathrm{a}$ \\
\hline DMS & 0,35 & 0,12 & 1,63 & 3,55 \\
\hline
\end{tabular}

"Médias seguidas da mesma letra, na coluna, não diferem entre si, pelo teste de Tukey, a 5\% de probabilidade.

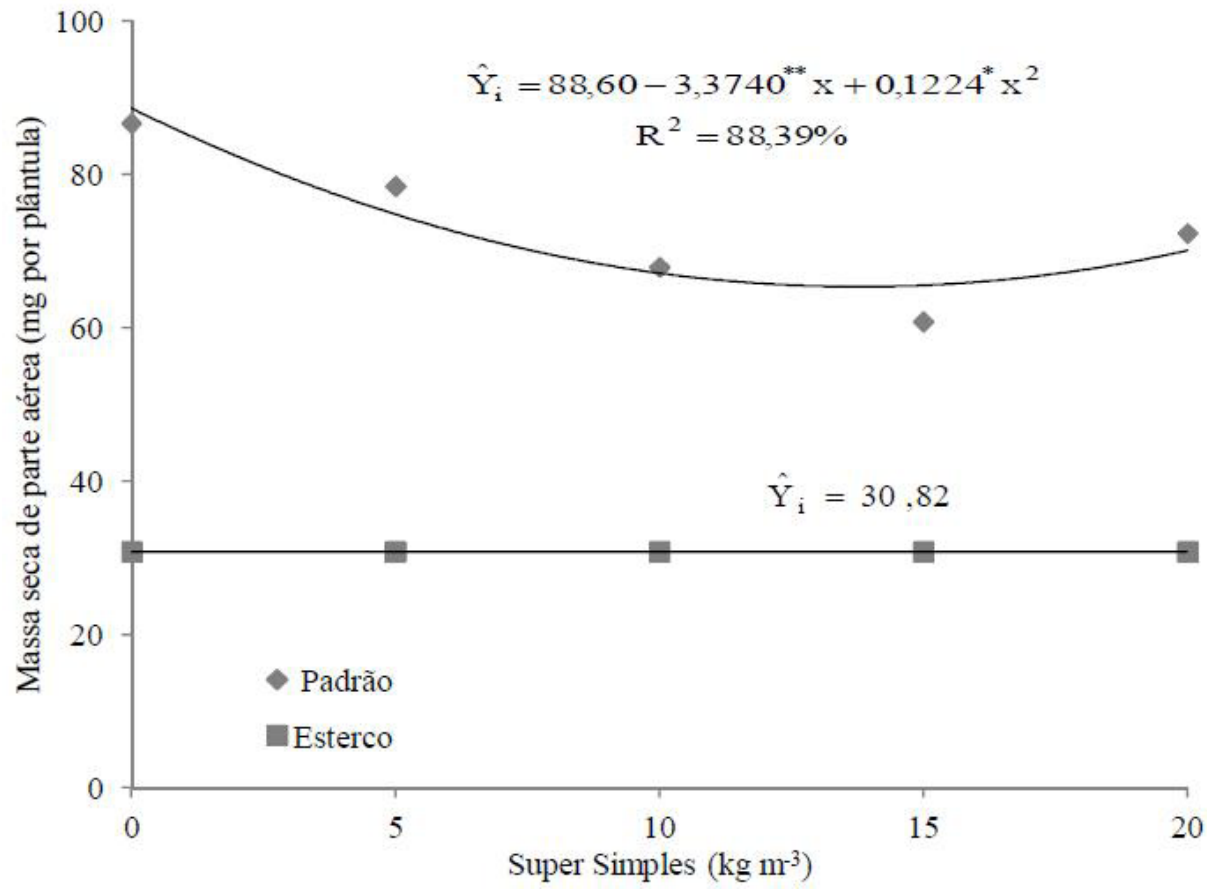

FIGURA 1 - Massa da parte aérea de plântulas de mamoeiro 'THB', submetidas a diferentes doses de esterco de galinha e superfosfato simples $(*, * *$ Coeficiente significativo a 5 e $1 \%$, respectivamente, pelo teste de $\mathrm{t}$ ). 


\section{CONCLUSÃO}

Pode-se concluir que a adição de esterco de galinha e de superfosfato simples na mistura-padrão (substrato Bioplant ${ }^{\circledR}+$ fertilizante Basocote $^{\circledR}$ ) não melhorou a qualidade das mudas de mamoeiro 'THB', produzidas nas condições experimentais adotadas.

\section{REFERÊNCIAS}

ABAD, M.; NOGUEIRA, P.; BURÉS, S. National inventory of organic wastes for use as growi media for ornamental potted plant production: case study in Spain. BioresourceTechnology, Miramar, v,77, p.197-200, 2001.

ARAÚJO, W.B.M. de; ALENCAR，R.D.; MENDONÇA, V.; MEDEIROS, E.V. de;ANDRADE, R. de C.; ARAÚJO, R.R. de .Esterco caprino na composição de substratos para a formação de mudas de mamoeiro. Ciência e Agrotecnologia, Lavras, v.34, n.1, p.68-73, 2010.

BAYER, C.; MIELNICZUK, J. Dinâmica e função da matéria orgânica. In: SANTOS, G. de A.; SILVA, L.S. da; CANELLAS, L.P.; CAMARGO, F.A.O. (Ed.). Fundamentos da matéria orgânica do solo em ecossistemas tropicais e subtropicais. 2.ed. rev. e atual. Porto Alegre: Metrópole, 2008. p.7-18.

CANESIN, R.C.F.S.; CÔRREA, L. de S. Uso de esterco associado à adubação mineral na produção de mudas de mamoeiro (Carica papaya L.). Revista Brasileira de Fruticultura, Jaboticabal, v.28, n.3, p.481-486, 2006.

COSTA, E.; LEAL, P.A.M.; MESQUITA, V. do A.G.; SASSAQUI, A.R. Efeito do organosuper ${ }^{\circledR} \mathrm{e}$ do ambiente protegido na formação de mudas de mamoeiro. Engenharia Agrícola, Jaboticabal, v.31, n.1, p.41-55, 2011.

COSTA, E.; LEAL, P.A.M.; SANTOS, L.C.R. dos; VIEIRA, L.C.R. Crescimento de mudas de mamoeiro conduzidas em diferentes ambientes protegidos, recipientes e substratos na região de Aquidauana, Estado do Mato Grosso do Sul. Acta Scientiarum Agronomy, Maringá, v.32, n.3, p.463-470, 2010a.
COSTA, E.; MESQUITA, V. do A.G.; LEAL, P.A.M.; FERNANDES, C.D.; ABOT, A.R. Formação de mudas de mamão em ambiente de cultivo protegido em diferentes substratos. Revista Ceres, Viçosa, MG, v.57, n.5, p.679-685, 2010 b.

CRUZ, C.D. Programa genes: estatística experimental e matrizes. Viçosa: UFV, 2006. 346p.

DIAS, D.C.F. dos S.; ESTANISLAU, W.T.; FINGER, F.L.; ALVARENGA, E.M.; DIAS, L.A. dos S. Physiological and enzymatic alterations in papaya seeds during storage. Revista Brasileira de Sementes, Londrina, v.32, p.148-157, 2010.

FAO. FAOSTAT. Disponível em: $\leq$ http:// faostat.fao.org/site/567/Desktop Default. aspx?PageID=567\#ancor $>$. Acesso em: 30 abr. 2012.

HIGASHIKAWA, F.S.; SILVA, C.A.; BETTIOL, C. Chemical and physical properties of organic residues. Revista Brasileira de Ciências do Solo, Viçosa, MG, v.34, p.1.743-1.752, 2010.

LABOURIAU, L.G.; VALADARES, M.E.B. On the germination of seeds Calotropis procera (Ait.) Ait.f. Anais da Academia Brasileira de Ciências, Rio de Janeiro, v.48, n.2, p.263-284, 1976.

LANA, R.M.Q.; SANTOS, C.M.; SANTOS, V.L.M.; BARBIZAN, E.L.; MENDES, A.F. Utilização de diferentes substratos e de fertilizantes de liberação lenta na produção de mudas do cafeeiro em saquinhos. Revista Ceres, Viçosa, MG, v.49, n.286, p.577-586, 2002.

MAGUIRE, J.D. Speed of germination - aid in selection and evaluation for seedling emergence and vigor. Crop Science, Madison, v.2, n.2, p.176-177, 1962.

MARTINS, C.N.; PEREIRA, M.G.; SILVA, R.F. da; OLIVEIRA, A.C.S. de; SILVA, F. da. Efeito do pólen nas características físicas e fisiológicas de sementes de mamão. Revista Brasileira de Sementes, Viçosa, MG, v.31, n.2, p.19-26, 2009.

MARTINS, C.N.; SILVA, R.F. da; PEREIRA, M.G.; ARAÚJO, E.F.; POSSE, S.C.P. Influência do repouso pós-colheita de frutos na qualidade fisiológica de sementes de mamão. Revista Brasileira de Sementes, Viçosa, MG, v.28, n.2, p.142-146, 2006. 
MENDONÇA, V.; ABREU, N.A.A. de; GURGEL, R.L. da S.; FERREIRA, E.A.; ORBES, M.Y.; TOSTA, M. da S. Crescimento de mudas de mamoeiro 'Formosa' em substratos com utilização de composto orgânico e superfosfato simples. Ciência e Agrotecnologia, Lavras, v.30, n.5, p.861-868, 2006a.

MENDONÇA, V.; PEDROSA, C.; FELDBERG, N.P.; ABREU, N.A.A. de; BRITO, A.P.F. de; RAMOS, J.D. Doses de nitrogênio e superfosfato simples no crescimento de mudas de mamoeiro 'Formosa'. Ciência e Agrotecnologia, Lavras, v.30, n.6, p.1.065-1.070, 2006 b.

NEGREIROS, J.R. da S.; BRAGA, L.R.; ÁLVARES, V. de S.; BRUCKNER, C.H. Diferentes substratos na formação de mudas de mamoeiro do grupo solo. Revista Brasileira de Agrociência, Pelotas, v.11, n.1, p.101-103, 2005.

PEREIRA, W.E.; LIMA, S.F.; PAULA, L.B.; ALVAREZ, V.V.H. Crescimento e composição mineral de mudas de maracujazeiro em função de doses de osmocote em dois tipos de substratos. Revista Ceres, Viçosa, MG, v.47, n.271, p.311-324, 2000.

ROSOLEM, C.A.; WITACKER, J.P.T.; VANZOLINI, S.; RAMOS, V.J. Significance of root growth on cotton nutrition in an acidic low-P soil. Plant and Soil, Dordrecht, v. 212, p.185-190, 1999.
SERRANO, L.A.L.; CATTANEO, L.F.; FERREGUETTI, G.A. Adubo de liberação lenta na produção de mudas de mamoeiro. Revista Brasileira de Fruticultura, Jaboticabal, v.32, n.3, p.874-883, 2010 .

SERRANO, L.A.L.; SILVA, C.M.M.; OGLIARI, J.; CARVALHO, A.J.C.; MARINHO, C.S.; DETMANN, E. Utilização de substrato composto por resíduos da agroindústria canavieira para produção de mudas de maracujazeiro-amarelo. Revista Brasileira de Fruticultura, Jaboticabal, v.28, n.3, p.487-491, 2006.

TOKUHISA, D.; DIAS, D.C.F. dos S.;ALVARENGA, E.M.; HILST, P.C.; DEMUNER, A.J. Compostos fenólicos inibidores da germinação em sementes de mamão (Carica papaya L.). Revista Brasileira de Sementes, Viçosa, MG, v.29, p.161-168, 2007.

TOKUHISA, D.; DIAS, D.C.F. dos S.;ALVARENGA, E.M.; DIAS, L.A. dos S.; MARIN, S.L.D. Época de colheita dos frutos e ocorrência de dormência em sementes de mamão (Carica papaya L.). Revista Brasileira de Sementes, Viçosa, MG, v.30, p.7580, 2008. 